\title{
RESULTADOS PRELIMINARES EN TAMBOS DEL NORESTE DE LA PROVINCIA DE SANTA FE (ARGENTINA): CALIDAD DE AGUA Y CONTAMINACIÓN ${ }^{a}$
}

\author{
BAdino, O. ${ }^{1 ;}$ ThOMAS, J.A. ${ }^{1}$; SCHMIDT, E. ${ }^{2}$; \\ Ramos, E. ${ }^{2}$; WeIDMANN, R. ${ }^{1} \&$ JaUREgUI, J. ${ }^{1}$
}

\begin{abstract}
RESUMEN
El noreste de la provincia de Santa Fe, es un área extracuenca con buen potencial para producir leche. Se evaluó la calidad físico-química y microbiológica del agua para uso en el tambo, como bebida de animales y consumo humano en 10 tambos de los departamentos Vera, General Obligado, Norte de San Justo y San Javier. La calidad físico-química del agua cumple con los estándares para la producción de leche y bebida humana. Se presentó alta incidencia de contaminación microbiológica. El 60 \% de los tambos tienen recuentos de Coliformes Totales superiores al límite. En un 20 \% y 40 \% de los mismos se aisló Escherichia Coli y Pseudomonas Aeruginosa respectivamente, pudiendo dificultar la obtención de leche de calidad. Esto requiere de acciones correctivas tal como limpieza e higiene de tanques de almacenamiento de agua, tendientes a la eliminación de patógenos. Es importante promover la caracterización sistemática de las fuentes de agua en todas las cuencas lecheras.
\end{abstract}

Palabras clave: calidad agua, producción lechera, contaminación, Noreste de la provincia de Santa Fe.

\footnotetext{
ABSTRACT

Preliminary results in dairy farms of northeast Santa Fe province (Argentina): water quality and contamination.

Northeastern of Santa Fe, is one of the potential areas for dairy activity. The objective was to evaluate the physical, chemical and microbiological quality of water used in milking parlor and for drinking purposes for both animals and humans. This evaluation will determine the degree of contamination in 10 dairy farms from Vera, General Obligado, Northern San Justo and San Javier departments. The physical and chemical quality of water is good for dairy production and humans drinking. The $60 \%$ of dairy farms showed total coliform above the limit. Escherichia coli and Pseudomonas aeruginosa was isolated in the $20 \%$ and $40 \%$ of dairy farms respectively, that may

a.- Proyecto CAID 2011 PI 50120110100127. Universidad Nacional del Litoral

1.- Facultad de Ciencias Agrarias (UNL). Kreder 2805. (3080HOF) Esperanza, provincia de Santa Fe. Email: obadino@fca.unl.edu.ar

2.- Instituto Nacional de Tecnología Industrial (INTI) Lácteo. (2300) Rafaela, provincia de Santa Fe.

Manuscrito recibido el 20 de octubre de 2016 y aceptado para su publicación el 12 de diciembre de 2016.
} 


\section{O. Badino et al.}

hinder the possibilities to obtain good quality milk. It is important to promote the systematic characterization of water sources in all milksheds.

Key words: Water quality, contamination, milk production. North East of Santa Fe Province.

\section{INTRODUCCIÓN}

Los sistemas de producción ganadera en la Argentina están marcados por la pronunciada heterogeneidad ambiental que existe entre las diferentes regiones productivas. Si bien la producción lechera se encuentra concentrada en la región denominada Pampa Húmeda, existen otras regiones denominadas "extra cuencas" donde la misma es incipiente. Santa Fe es la segunda provincia productora de leche del país, representando el $28 \%$ del total nacional. La cuenca lechera santafesina -ubicada en el centro oeste- constituye la región productora más importante de América Latina, con alrededor de 4.300 tambos y 577.000 vacas que producen más de 2600 millones de litros de leche (13).

La producción de leche es una de las actividades ganaderas que mayor cantidad y mejor calidad de agua demanda. Su relevancia está relacionada a tres aspectos fundamentales: el agua como factor en la salud y nutrición del animal, el agua como elemento para la higiene en el tambo y el agua como factor en la salud de la población rural involucrada (22, 15). La principal fuente de agua para los tambos es la subterránea. Ésta proviene de perforaciones, donde la calidad presente dependerá del caudal, salinidad, tipo de sal y tóxicos presentes (24).

Las deficiencias en la construcción y manejo de las perforaciones, las fuentes de contaminación cercanas a los pozos (corrales y lagunas) y el desconocimiento de los productores sobre el manejo del agua y los efluentes, son causa de contaminación (27). El agua subterránea puede presentar alto contenido en nitratos provenientes de contaminación antropogénica, especialmente si los acuíferos no son profundos (20).

Otro aspecto es la calidad del agua para el lavado, tanto de la máquina de ordeño como de los utensilios. La dureza y la contaminación microbiológica del agua son factores importantes a considerar para la producción de leche de buena calidad. Las aguas duras disminuyen la eficiencia de limpieza en las ordeñadoras (28). Esta situación junto a una alta concentración de Sólidos Totales Disueltos (STD) corroe los caños e instalaciones, disminuyendo su vida útil (25).

La contaminación microbiológica puede tener incidencia, tanto en la calidad de la leche por favorecer focos de contaminación en partes de la máquina de ordeño (28), como en la salud de la población residente en las zonas rurales. La presencia de bacterias como Escherichia coli, pueden causar mastitis, afectando la salud animal y la calidad de leche (25).

Las exigencias de las industrias lácteas, referente a la calidad de agua en los tambos es cada vez mayor. Una de las condiciones requeridas para poder exportar a la Unión Europea, es tener agua de calidad "potable", siendo esta calidad regulada a partir de las normas establecidas por el Código Alimentario Argentino (8, 21; 18). La leche es considerada como uno de 